International Journal of Human and Health Sciences Vol. 02 No. 01 January’18

Case Report

\title{
A Rare Schwannoma Of The Submandibular Gland: A Case Report
}

Nasir MSNM ${ }^{1-3}$, Susibalan $B^{2}$, Soleh $M N M^{3}$, Salleh $N_{H} M^{4}$, Mohamad I

\begin{abstract}
:
Schwannomas are benign tumors arising from Schwann cells of the sheaths of peripheral nerves. Although vagus nerve and sympathetic chain composed of sympathetic fibers is one of the most common sites of schwannomas in extracranial head and neck region, many cases of origin unknown schwannomas were reported.

We report an unusual rare case of a submandibular gland schwannoma in a 67-year-old lady, who was successfully treated by surgical excision with no cranial nerve deficits and complete resolution of the symptoms postoperatively.

In this report, we establish a rare findings of schwannoma of the submandibular gland and to the best of our knowledge, this is the first case-report of schwannoma of submandibular gland reported from a tertiary hospital in the east coast of Malaysia.
\end{abstract}

Kevwords: Benign; schwannoma; submandibular gland.

International Journal of Human and Health Sciences Vol. 02 No. 01 January'18 Page : 38-40

\section{Introduction:}

Schwannomas are benign, solitary and welldifferentiated tumors of Schwann cells, originating from the sheath of myelinated nerve fibers. About $10-40 \%$ of extracranial schwannomas were not identified with the nerve origin ${ }^{1,2,3}$. Although schwannomas can arise from any nerve in the body, the most common locations include the head and neck area, contributed nearly $45 \%{ }^{3}$. Schwannomas of the submandibular gland are rare causes of extracranial neurogenic tumours ${ }^{4}$. These tumors rarely shows rapid progression. Usually it'sslow growing tumours with slight female predominance and usually present between second to fourth decades of life ${ }^{5}$. Neurological symptoms, progressive pain and malignant transformation are rare presentation ${ }^{5}$. Because of its nature that resistance to radiotherapy, surgical excision is necessary for optimal treatment of benign schwannomas, which usually results in complete resolution of symptoms ${ }^{5}$.

\section{Case Summary:}

A 67-year-old female with underlying hypertension and diabetes mellitus, was referred to Ear, Nose and Throat (ENT) department with 2 year history of painless left submandibular swelling. Swelling was increasing gradually with time. It was not associated with history of weight loss, dysphagia, and difficulty in mastication or fever.

A physical examination of her neck revealed a firm, smooth surfaced mass of $6 \mathrm{~cm} \times 4 \mathrm{~cm}$ in its diameter; which was non tender and located over

1. Mohd Shaiful Nizam Mamat Nasir, Department of Otorhinolaryngology, Hospital Tengku Ampuan Afzan, 25100 Kuantan, Pahang, Malaysia \& Department of Otorhinolaryngology-Head \& Neck Surgery, School of Medical Sciences, Universiti Sains Malaysia Health Campus, 16150 Kota Bharu, Kelantan, Malaysia

2. Bathma Dhevi Susibalan, Department of Otorhinolaryngology, Hospital Tengku Ampuan Afzan, 25100 Kuantan, Pahang, Malaysia.

3. Mohd Najeb Md Soleh, Department of Otorhinolaryngology, Hospital Tengku Ampuan Afzan, 25100 Kuantan, Pahang, Malaysia.

4. Nor Hafliza Md Salleh, Department of Pathology, Hospital Tengku Ampuan Afzan, 25100 Kuantan, Pahang, Malaysia

5. Irfan Mohamad, Department of Otorhinolaryngology-Head \& Neck Surgery, School of Medical Sciences, Universiti Sains Malaysia Health Campus, 16150 Kota Bharu, Kelantan, Malaysia

Correspondence to: Mohd Shaiful Nizam Mamat Nasir, Department of Otorhinolaryngology-Head \& Neck Surgery, School of Medical Sciences, Universiti Sains Malaysia Health Campus, 16150 Kota Bharu, Kelantan, Malaysia \& Department of Otorhinolaryngology, Hospital Tengku Ampuan Afzan, 25100 Kuantan, Pahang, Malaysia E-mail: drshaiful10@gmail.com 


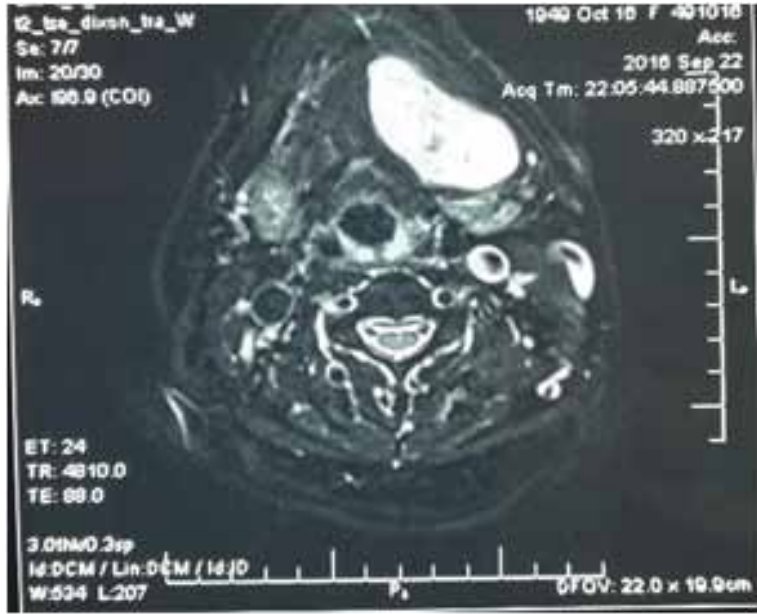

Figure 1: Hyperintense mass tumor at left submandibular gland. ( MRI T2-weighted image)

Intraoperatively, the mass was carefully dissected from the adjacent structures. Complete excision of the mass and submandibulectomy was performed with extra care was taken to identify and preserve the hypoglossal and lingual nerve (Figure 2).The surgical defect was closed in 2 layers with a surgical drain in situ.

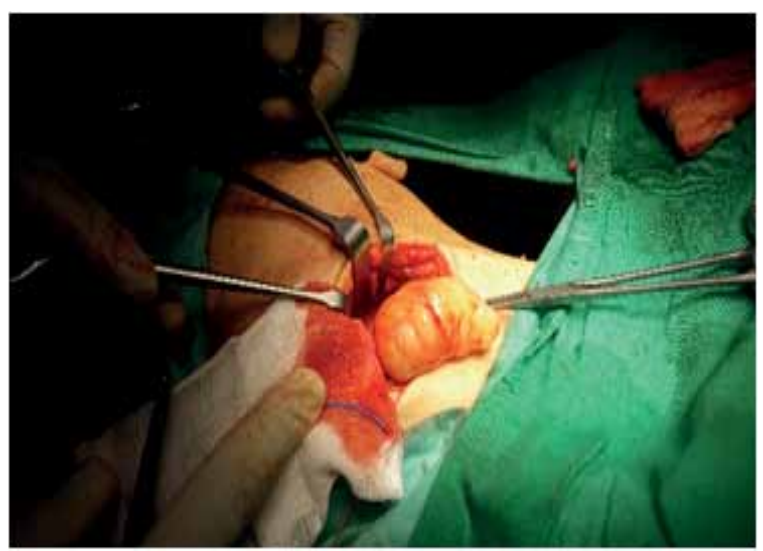

Picture 2: Complete removal of submandibular schwannoma

the left submandibular region. Overlying skin was normal. There were no sinus openings. No regional lymphadenopathy was detected. All the cranial nerve examination were unremarkable. Ear, Nose and Throat examination including flexible nasolaryngopharyngoscopy (FNLPS) was normal.

Ultrasonography (USG) neck revealed welldefined heterogeneously hypoechoic lesion seen medial to the left submandibular gland,measuring $2.5 \times 2.8 \times 3.6 \mathrm{~cm}$. Magnetic Resonance Imaging (MRI) neck was done in view of the lesion

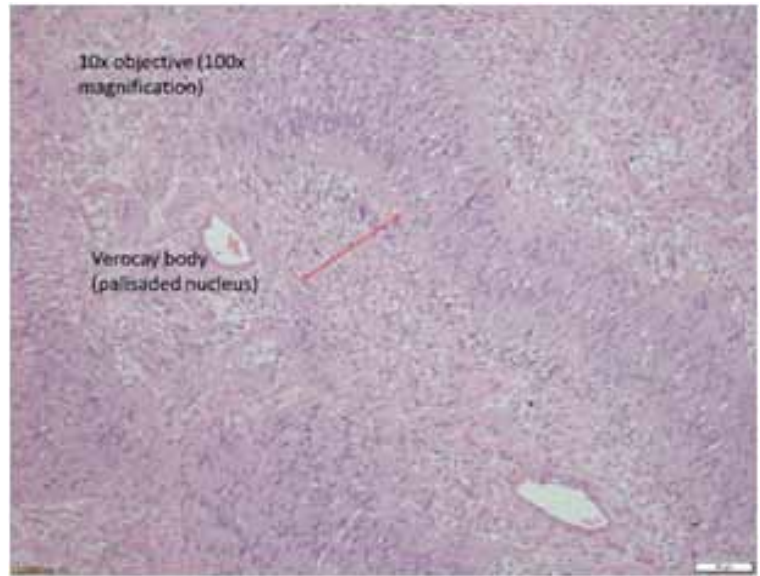

Figure 3: spindle cell lesion with Antoni A and Antoni $\mathrm{B}$ area with Verocay body (arrow). (H\&E, 10x objective)

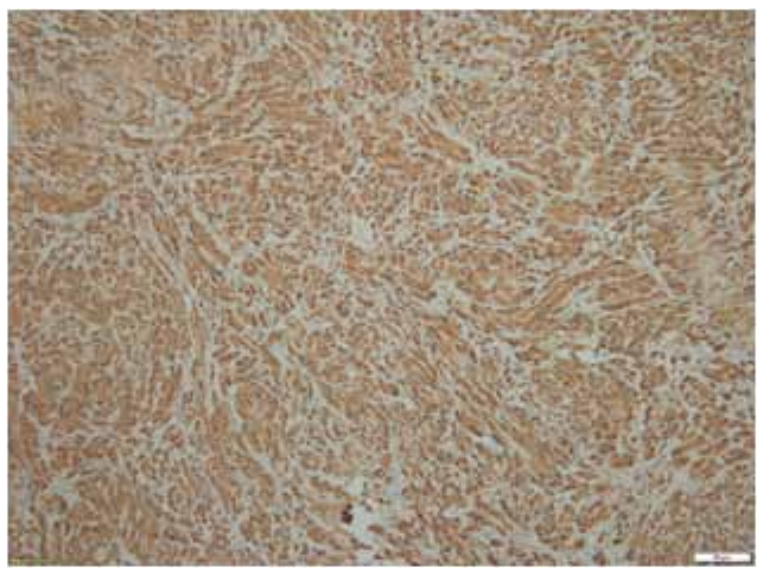

Figure 4: Strong and diffuse staining for S100 (20x objective)

being a soft tissue tumour and to extrapolate the relationship of the mass to the surrounding structure along with surgical mapping prior to excision. The MRI findings on T2-weighted image, the mass showed a hyperintense tumor possible neurogenic tumour at submandibular gland (Figure1) Fine needle aspiration cytology (FNAC)was inconclusive. A thorough discussion was done with patient and surgical excision of the mass under general anaesthesia was decided.

Histopathological examination of the specimen revealed spindle cell tumourmade up of predominantly cellular (Antoni A) areas mixed with hypocellular (Antoni B) areas. The cellular spindle cell areas exhibit round to oval nuclei with moderate pleomorphism and areas of palisaded nuclei (Verocay body), meanwhile the hypocellular area is composed of loose fibrocollagenous tissue with few scattered lesional cells (Picture 3). The tumor cells showed diffuse, strong positivity for S-100 protein (Picture 4) confirming the diagnosis 
of Schwannoma.

Patient was well post operatively and the surgical drain was removed day two postoperative. She was discharged well with oral antibiotics for seven days. Currently at six months post-operative, our patient is well with no evidence of a recurrence swelling. There are no reported complications.

\section{Discussion:}

Schwannomas can arise from all cranial nerves (except $\mathrm{CN}$ I and CN II), with CN VIII being the most common. Other locations include spinal nerve roots, flexor surfaces of upper and lower extremities, and tongue ${ }^{1,2}$. Although most schwannomas are known to be solitary, there is an association with neurofibromatosis type 2 .This is contrary with our patient, whoma well without any is known comorbids or any genetic disposition.

Schwannomatosis is a well-established third form of neurofibromatosis, characterized by the presence of multiple non-vestibular, nonintradermal schwannomas, often associated with chronic pain ${ }^{3}$. Schwannomas are growing, solitary neoplasms of Schwann cell origin. In the head and neck region they occur most commonly in the internal acoustic meatus, with most of them were benign schwannomas, with only one was reported as malignant schwannoma ${ }^{4}$

In our patient, FNAC was not helpful for diagnosis, and we believe FNAC guided by ultrasound is needed for a more informative cytology, as has been reported with other cases ${ }^{7,8}$. The pattern on and MR images shows more of myxomatous tissue which raise a possibility of it not being a simple benign tumour ${ }^{8,9}$

Treatment should be confined to complete surgical excision, and wide excision is not recommended. Longterm follow-up of the schwannomas shows few schwannomas recur after complete excision ${ }^{10}$. Schwannomas rarely develop in outside the usual cranial nerve distribution and we present an unsual case of schwannoma occurring in the major salivary gland. Fine-needle aspiration cytology is useful, however, we must take care of the potential pitfalls in diagnosis. Schwannomas are best managed by complete surgical excision, as seen by our patient.

\section{Conclusion:}

Although schwannoma at submandibular region is very rare, as in our present case, but it should be taken into consideration on making one of the differential diagnosis when treating a patient with slow growing mass with inconclusive finding of cytology result. We strongly believe that total excision of the tumor via an external approach is optimal treatment for schwannoma of the submandibular gland since its show excellent postoperative recovery.

\section{Referrences:}

1. Al-Ghamdi S, Black MJ, Lafond G. Extracranial head and neck schwannomas. J Otolaryngol 1992; 21:186-8.

2. Sharaki MM, Talaat M, Hamam SM. Schwannoma of the neck. Clin Otolaryngol 1992; 7:245-51.

3. Aslan et al.: Schwannoma of the submandibular gland: a case report. Journal of Medical Case Reports 2014 8:231

4. Yafit D, Horowitz G, Vital I, et al. An algorithm for treating extracranial head and neck schwannomas. Eur Arch Otorhinolaryngol 2015;272:2035-8

5. Dhupar A, Yadaw S, Dhupar V. Schwannoma of the hard plate: a rare case. Internet J Head Neck Surg. 2011:4

6. Piscioli F, Antolini M, Pusiol T, Dalri P, Lo Bello MD,
Mair K. Malignant schwannoma of the submandibular gland. A case report. J Otorhinolaryngol Relat Spec. 1986;48:156-161

7. M.E. Baser, J.M. Friedman, G.R. Evans, Increasing the specificity of diagnostic criteria for schwannomatosis, Neurology 66 (2006) 730-732.

8. P.C. Bondy, R.M. Block, J. Green, Ancient schwannoma of the submandibular gland: a case report, Ear Nose Throat J. 75 (1996) 781-783.

9. M.K. Chan, L.J. McGuire, Cytodiagnosis of lesions presenting as salivary gland swellings: a report of seven cases, Diagn. Cytopathol. 8 (1992) 439-443.

10. Di Benedetto,R. Ballarin,M. Spaggiari,A. Pecchi, G.E. Gerunda,Role ofintraoperative ultrasonography for pancreatic schwannoma, J. Surg. Oncol. 105 (2012) 859-860. 